Article

\title{
Investigating the Impact of Trade Disruptions on Price Transmission in Commodity Markets: An Application of Threshold Cointegration
}

\author{
Janelle Mann ${ }^{1, *}$ (i) and Derek Brewin ${ }^{2}$ \\ 1 Department of Economics, University of Manitoba, Winnipeg, MB R3T 2N2, Canada \\ 2 Department of Agribusiness and Agricultural Economics, University of Manitoba, \\ Winnipeg, MB R3T 2N2, Canada; derek.brewin@umanitoba.ca \\ * Correspondence: janelle.mann@umanitoba.ca
}

\section{check for} updates

Citation: Mann, Janelle, and Derek Brewin. 2021. Investigating the Impact of Trade Disruptions on Price Transmission in Commodity Markets An Application of Threshold Cointegration. Journal of Risk and Financial Management 14: 450. https://doi.org/10.3390/ jrfm14090450

Academic Editors: Shuddhasattwa Rafiq and Thanasis Stengos

Received: 31 July 2021

Accepted: 1 September 2021

Published: 20 September 2021

Publisher's Note: MDPI stays neutral with regard to jurisdictional claims in published maps and institutional affiliations.

Copyright: (c) 2021 by the authors. Licensee MDPI, Basel, Switzerland. This article is an open access article distributed under the terms and conditions of the Creative Commons Attribution (CC BY) license (https:/ / creativecommons.org/licenses/by/ $4.0 /)$.

\begin{abstract}
Threshold cointegration is introduced as an econometric technique to model the impact of trade disruptions on spatial price transmission in commodity markets so that market participants and policy makers can understand the global impact of trade disruptions on prices. The threshold cointegration technique that is employed is flexible in that it allows the number of thresholds and their location to be determined endogenously and the threshold variable to be exogenous to the system. We innovate on the threshold cointegration technique by selecting a measure of trade disruptions as the threshold variable. This innovation can be used for any commodity market that is spatially connected due to arbitrage; however, to illustrate its usefulness we apply the technique to trade disruptions for canola traded between Canada and China using weekly data between 2014 and 2019 and find that canola trade disruptions between Canada and China impacted global price transmission and resulted in market fragmentation.
\end{abstract}

Keywords: threshold cointegration; trade disruption; commodity prices; canola

JEL Classification: C32; F1; Q11; Q17

\section{Introduction}

Trade disruption in commodity markets is not rare. For example, there was a disruption of wheat traded between the US and Canada in the early 1990s (Alston et al. 1994) and between the US, EU, and Australia in the late 1990s (Balzer and Stiegert 1999). Similarly, trade disruption of beef and pork traded between the US and Canada took place in the early 2000s (Rude et al. 2006, 2007) and there has been longstanding disruptions of apples traded between New Zealand and Australia (Higgins and Dibden 2011) and softwood lumber traded between the US and Canada (Boyd and Krutilla 1987). Reasons for the trade disruptions listed as examples include quotas, domestic subsidies, boarder closures due to bovine spongiform encephalopathy (BSE), country of origin labelling and biosecurity. These examples highlight the importance of having an appropriate model to investigate the impact of trade disruptions on spatial price transmission in commodity markets so that market participants and policy makers can understand the global impact on prices.

This paper introduces threshold cointegration as an econometric technique to model the impact of trade disruptions on spatial price transmission in commodity markets and applies threshold cointegration to trade disruptions of canola traded between Canada (currently the world's largest canola exporter) and China (currently the world's second largest canola importer and Canada's largest buyer). The application of threshold cointegration to investigate spatial price transmission in commodity markets has been used to investigate wholesale coarse rice in Nepal and India (Sanogo and Amadou 2010), black and white pepper in Malaysia (Sephton 2011) and wheat and flour prices in Afghanistan 
(Hassanzoy et al. 2017). Each study includes a single threshold. We improve on previous threshold cointegration applications by employing a flexible threshold cointegration technique that allows the number of thresholds and their location to be determined endogenously and the threshold variable to be exogenous to the system. We innovate on previous threshold cointegration techniques by incorporating trade disruptions into the model as the threshold variable. To illustrate the usefulness of this innovation to market participants and policy makers we apply the innovation to recent trade disruptions for canola traded between Canada and China.

The remainder of the paper is structured as follows: Section 2 provides details on a specific threshold cointegration technique that allows an exogenous measure of trade dispute to be incorporated as a threshold variable. Section 3 applies the method to investigate the impact of trade disruptions between Canada and China on price transmission in global prices of canola. Section 4 discusses the data, results of the application, and limitations. Section 5 concludes.

\section{Method}

The first step in the threshold cointegration technique is to investigate the order of integration ${ }^{1}$ of each series using unit root or stationarity tests such as the augmented Dickey Fuller (ADF) unit root test (Dickey and Fuller 1979, 1981). Arltová and Fedorová (2016) provide a helpful guide for selecting the most appropriate test given the properties of the underlying time series. If the series are found to be integrated of the same order, the threshold cointegration technique of Sephton and Mann (2013) can be applied. The mathematical representation of the threshold cointegration technique is:

$$
\begin{gathered}
Y_{t}=\beta_{1}+\beta_{2} \text { Trend }_{t}+\beta_{3} X_{t}+\varepsilon_{t} \\
\Delta \varepsilon_{t}=\delta_{1} \varepsilon_{t-1} I\left(P_{t-1}<\tau_{1}\right)+\delta_{2} \varepsilon_{t-1} I\left(\tau_{1}<P_{t-1}<\tau_{2}\right)+\delta_{3} \varepsilon_{t-1} I\left(\tau_{2}<P_{t-1}\right)+ \\
\sum_{i=1}^{p} \alpha_{i} \Delta \varepsilon_{t-i}+v_{t}
\end{gathered}
$$

where:

- $Y_{t}$ and $X_{t}$ are the canola price ratios.

- $\quad P_{t}$ is the proportion of total Canadian canola exports that are imported by China.

- $\tau_{1}<\tau_{2}$ are the thresholds that divide observations in to the bottom, middle and top regimes.

- $\mathrm{I}()$ is the Heaviside indicator function.

- $\Delta$ is the difference operator.

The top equation is the long run relationship between the canola price ratios. The bottom equation is the threshold cointegration test which builds on the traditional cointegration test of Engle and Granger (1987). The threshold cointegration test is similar to the Engle and Granger (1987) approach in that it examines the residual series from the long run relationship. If thresholds exist (for expository purposes, we assume that there are two thresholds, denoted by $\tau_{1}$ and $\tau_{2}$ ), they examine the null hypothesis of $\delta_{1}=\delta_{2}=$ $\delta_{3}=0$ against the alternative that they are not jointly zero. If thresholds do not exist the equation collapses and becomes equivalent to that of Engle and Granger (1987) with a null hypothesis of no cointegration. Inference for threshold cointegration tests use residual block based bootstrapping.

The threshold cointegration technique of Sephton and Mann (2013) endogenously determines both the number of thresholds and their locations using an information criteria loosely following Gonzalo and Pitarakis (2002). Here we allow for as many as three thresholds, and as few as zero. This threshold cointegration technique is unique because it allows the threshold variable to be exogenous to the system. However, the threshold variable must be stationary. If the threshold variable is not stationary in levels, one can use its first difference. This parallels the TAR and MTAR models by Enders and Siklos (2001). We use the proportion of total Canadian canola exports that are imported by China as the threshold 
variable. If the procedure chooses two thresholds, they may be symmetric about zero, but this decision is not determined a priori-the data determine the number of thresholds and their locations. While this approach could choose a specification similar to the traditional band-TAR model described by Balke and Fomby (1997), it is very flexible and has been shown to have desirable size and power properties. For further details on the threshold cointegration technique and its properties please refer to Sephton and Mann (2013).

\section{Application to Canola Trade Dispute}

The Canadian market for canola, or rapeseed as it is referred to in international discussions, is highly reliant on the movement of seed from Canada to Asia. Canola protein is not regarded as a premium protein source, but its oil brings a premium because of its high smoking point and low saturated fat. Canada and Australia are the only countries with significant surplus in canola production, with Canada exporting around 10 million metric tonnes and Australia exporting 2 million metric tonnes. Africa and South America do not trade significantly in the market and the EU is a net importer. For most of the last decade the EU did not import food ready canola from Canada because of its genetically modified organism (GMO) food regulations. Canada found enough demand from Asia and the US while Australia created two marketing chains so that it could meet the non-GMO demand from the EU. Since 2020 Canada has been moving more canola to the EU as supply for the biodiesel market.

Over the past decade there have been several trade disruptions for canola traded between Canada and China, most being attributed to noncompliance with China's plant health requirements that has led to a ban on canola imports from two major Canadian canola exporters. Cardwell and Brewin (2019) and Wells and Slade (2021) provide specific details of the 2019 trade disruptions with the ensuing WTO dispute consultation. Some attribute the trade disruptions to geopolitics including Meng Wanzhou's extradition and Dalai Lama's visit to Canada. No matter the cause, the trade disruptions impacted the flow of canola globally. We apply threshold cointegration to model the impact of trade disruptions on price transmission in global prices for canola.

Cardwell and Brewin (2019) suggested that the impacts of the trade dispute depend on the ability of China to replace exports with other suppliers. The Food and Agricultural Organization of the United States (2021) reports Canada had a drop in exports from 10.5 to 8.6 million metric tonnes from 2018 to 2019 while Asia had a drop in imports from 9 million metric tonnes to 7.1 million metric tonnes. With exports from Australia totalling 1.6 million metric tonnes, it is possible that all of Australia's exports shifted away from the EU toward Asian markets. However, with the major drop in the size of Asia's import demand, it appears that to some extent the world trade patterns have shifted to be more alike the virtual autarky option in Cardwell and Brewin (2019) than the relatively low impact scenario of all Chinese imports being supplied by other markets.

This application investigates the impact of trade disruptions between Canada and China on price transmission in global prices for canola between 2014 and 2019 by testing for threshold cointegration between two price ratios: Vancouver/Rouen and Vancouver/Kwinana. The Vancouver price represents the price in Canada, the Rouen price represents the price in the EU, the Kwinana price represents the price in Australia. The Kwinana price is that for GMO canola and trades at a discount to non-GMO canola. The proportion of total Canadian canola exports that are imported by China is used as the threshold variable and ranges between 0.080 and 0.597 . The most recent trade disruption is visibly obvious in Figure 1. 


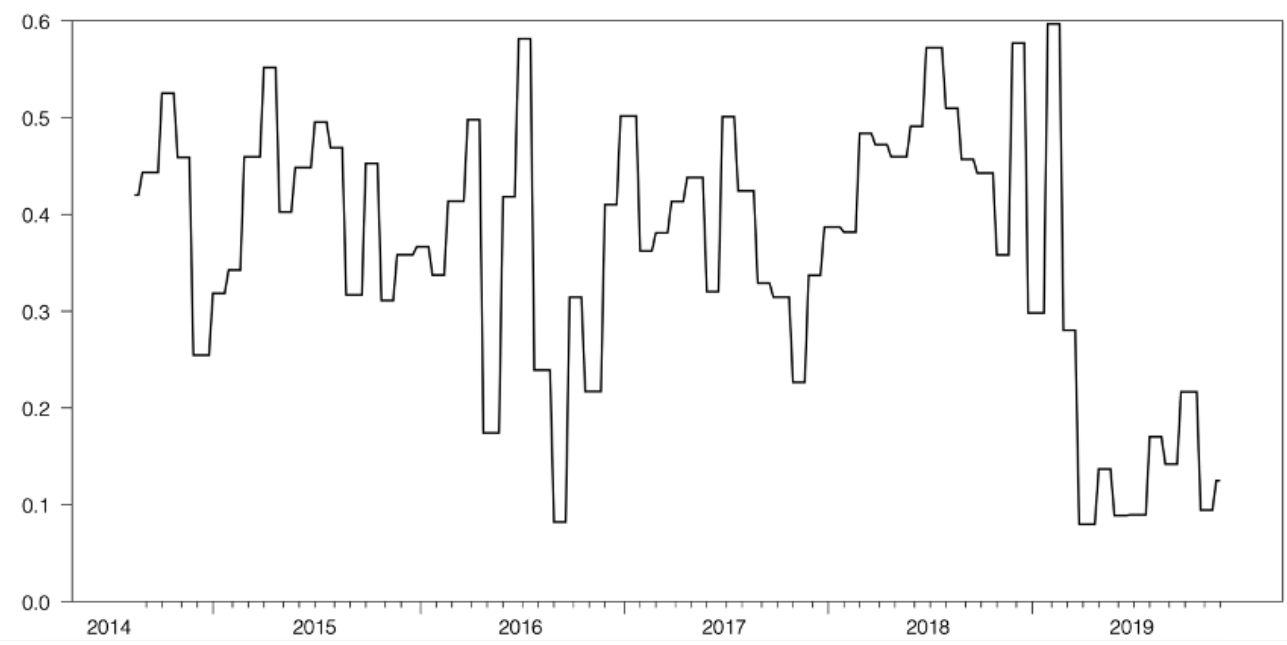

Figure 1. Proportion of Total Canadian Canola Exports that are Imported by China.

\section{Data and Results}

The empirical application incorporates weekly data from the Tuesday of each week between September 30, 2014 and December 3, 2019. Canola prices for Vancouver, Rouen and Kwinana are from Leftfield Commodity Research (2020) and converted to USD before creating the Vancouver/Rouen and Vancouver/Kwinana price ratios. The threshold variable is a proportion with the quantity of Canadian canola exported to China in the numerator and the quantity of Canadian canola exported to all destinations in the denominator using monthly data from Statistics Canada (2021). Monthly data for the threshold variable is converted to weekly data by filling each Tuesday with its respective monthly value.

Table 1 provides summary statistics for the canola price ratios and the proportion of total Canadian canola exports that are imported by China. Both the the mean and the standard deviation for the Vancouver/Rouen price ratio are higher than the Vancouver/Kwinana price ratio. Figure 2 depicts the canola price ratios; the Vancouver/Rouen is larger than the Vancouver/Kwinana price ratio for all observations except September 30 and October 14, 2014. The spread between the canola price ratios varies throughout the time period, with an ocular inspection revealing the spread increases during periods of trade disruptions as measured by the proportion of total Canadian canola exports that are imported by China. The correlation between the spread and trade disruptions is -0.793 .

Table 1. Summary Statistics.

\begin{tabular}{cccc}
\hline Variable & Mean & Std Dev & Range \\
\hline Proportion of Total Canadian Canola & 0.361 & 0.137 & 0.517 \\
Exports that are Imported by China & 0.945 & 0.062 & 0.291 \\
Vancouver/Rouen Price Ratio & 1.046 & 0.056 & 0.322 \\
Vancouver/Kwinana Price Ratio & & \\
\hline
\end{tabular}

The results from the empirical application are presented in the same order as Section 2: Method and are followed by a discussion of the limitations. Table 2 contains results from ADF unit root tests and provides evidence that the price ratios are I(1) (i.e., first difference stationary) and the measure of trade disruptions is $\mathrm{I}(0)$. The results satisfy the necessary criteria, thus we continue by testing for threshold cointegration. 


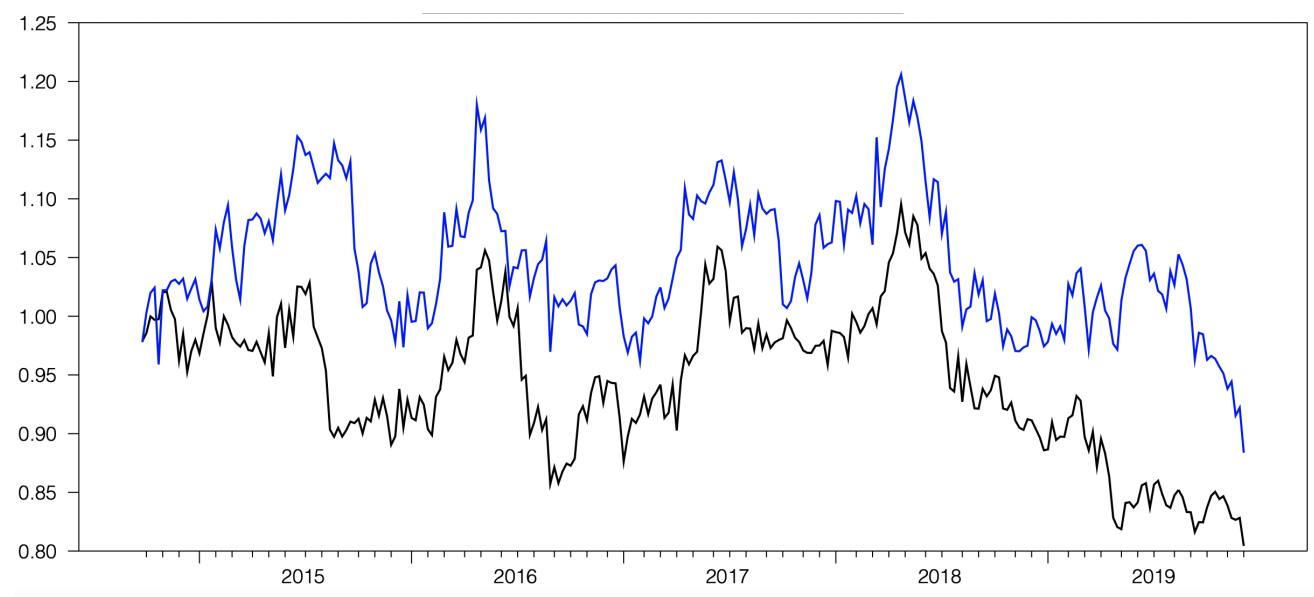

Figure 2. Canola Vancouver/Kwinana (blue) and Vancouver/Rouen (black) Price Ratios from 2014 to 2019 .

Table 2. Unit Root Test Results.

\begin{tabular}{ccc}
\hline Variable & Level & $\Delta$ \\
\hline Proportion of Total Canadian Canola & $-3.150^{*}$ & NA \\
Exports that are Imported by China & -2.724 & $-19.846^{* *}$ \\
Vancouver/Rouen Price Ratio & -2.819 & $-19.565^{* *}$ \\
Vancouver/Kwinana Price Ratio & & \\
\hline
\end{tabular}

Notes: The null hypothesis is a unit root. The deterministic components for level data are constant and trend and for differenced data $(\Delta)$ is a constant. The lag length for the unit root tests is selected by the AIC from a maximum of $T^{1 / 3}$. Significance at $\alpha=0.10,0.05$ and 0.01 denoted by * and **. 'NA' indicates we rejected the null hypothesis for the level series.

Figure 3 contains results from the threshold cointegration test and provides evidence that the price ratios are cointegrated (Seo Test Statistic $=54.24^{* * *}$ ). However, not all four regimes are cointegrated. This is a unique and telling finding. Within commodity markets it is common for the middle regime(s) not to be cointegrated because arbitrage of the physical commodity is not yet profitable due to transportation, insurance, and other transaction costs and is termed band-TAR by Balke and Fomby (1997). Cointegration is expected within the top and bottom regimes because arbitrage become profitable when the band is stretched. Here we find the top three regimes are cointegrated, but the bottom regime is not cointegrated. This means that during periods of trade disruptions (i.e., when the system is in the bottom regime) there is no movement back to the long run equilibrium. This provides evidence that the canola trade disruptions impacted global price transmission and resulted in market fragmentation. Policy makers need to be aware that the trade dispute between Canada and China has a ripple effect and impacts canola producers, buyers and sellers worldwide. An area left for future study is to estimate a threshold error correction model to investigate which of the series adjust to restore the long run equilibrium and whether there is a dominant price ratio. 


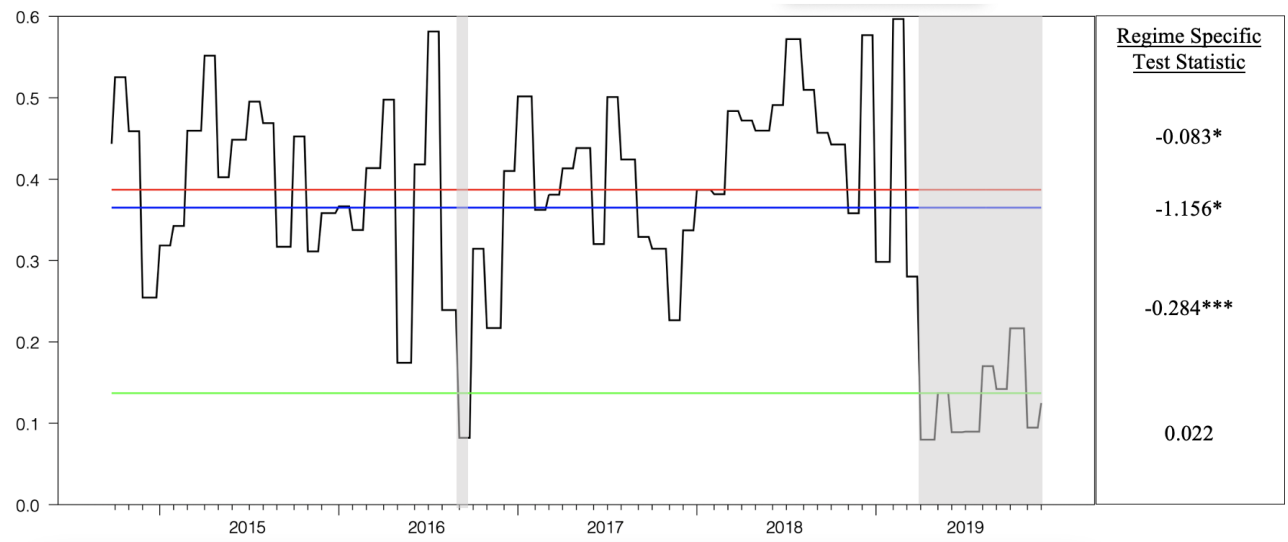

Figure 3. Threshold cointegration results with threshold variable overlay. Notes: Three thresholds $(0.137,0.365$, and 0.387$)$ were selected using the AIC from a maximum of three. The horizontal lines are the three endogenously determined thresholds. Test statistics for the null hypothesis of no cointegration for each regime are provided on the right hand side of the figure. The shaded areas indicate the time period for which the null hypothesis of no cointegration is rejected. Significance at $\alpha=0.10,0.05,0.01$ denoted by ${ }^{*}, * *$ and ${ }^{* * *}$.

Before continuing to the conclusion it is important to discuss limitations. The first limitation of the innovation is that the measure of trade disruptions must be continuous. This precludes a binary variable that is equal to 0 for periods without trade disruptions and 1 for periods with trade disruptions. Another limitation is that the threshold cointegration technique of Sephton and Mann (2013) requires that all variables be integrated of the same order. If the market for the specific commodity is efficient, this limitation is not restrictive, however there are many non-exchange-traded commodities that may not be operating in an efficient market.

\section{Conclusions}

This paper introduces threshold cointegration as an econometric technique to model the impact of trade disruptions on price transmission in commodity markets. The threshold cointegration approach by Sephton and Mann (2013) is novel because it allows between zero and three thresholds and endogenously selects the optimal number and their location using an information criteria loosely following Gonzalo and Pitarakis (2002). Thresholds divide the observations into different regimes based on the size of the threshold variable. The threshold variable can be any stationary variable. We innovate on the econometric technique by selecting a measure of trade disruptions as the threshold variable. Results from the cointegration tests can be used to determine the impact of trade disruptions on global price transmission. To illustrate its usefulness we apply the econometric technique to investigate the impact of trade disruptions for canola exported from Canada to China on global prices for canola. Threshold cointegration results provide evidence that the system contains three thresholds and is cointegrated, but there is no movement back to the long run equilibrium during periods of trade disruptions. This finding is indicative of market fragmentation.

Author Contributions: Conceptualization, Methodology, Software, Formal Analysis, WritingOriginal Draft Preparation, Writing-Review \& Editing: J.M.; Conceptualization, Data curation, Methodology, Formal Analysis, Writing_-Original Draft Preparation, Writing-Review \& Editing: D.B. All authors have read and agreed to the published version of the manuscript.

Funding: This research received no external funding.

Institutional Review Board Statement: Not applicable.

Informed Consent Statement: Not applicable. 
Data Availability Statement: Not applicable.

Acknowledgments: The authors would like to thank three anonymous referees and participants of the 2021 Canadian Agricultural Economics Association Annual Meeting for their helpful comments.

Conflicts of Interest: The authors declare no conflict of interest.

\section{Note}

1 The order of integration is the number of times a series must be differenced to be made stationary and is typically represented by the letter $\mathrm{d}$ and abbreviated $\mathrm{I}(\mathrm{d})$.

\section{References}

Alston, Julian M., Richard Gray, and Daniel A. Sumner. 1994. The wheat war of 1994. Canadian Journal of Agricultural Economics 42: 231-51. [CrossRef]

Arltová, Markéta, and Darina Fedorová. 2016. Selection of unit root test on the basis of length of the time series and value of AR(1) parameter. STATISTIKA 96: 47-64.

Balke, Nathan S., and Thomas B. Fomby. 1997. Threshold cointegration. International Economic Review 38: 627-45. [CrossRef]

Balzer, Brian, and Kyle W. Stiegert. 1999. The European Union-United States wheat gluten policy dispute. Journal of Food Distribution Research 30: 1-10.

Boyd, Roy, and Kerry Krutilla. 1987. The welfare impacts of U.S trade restrictions against the Canadian softwood lumber industry: A spatial equilibrium analysis. Canadian Journal of Economics 20: 17-35. [CrossRef]

Cardwell, Ryan, and Derek G. Brewin. 2019. Blackleg or blackmail? Economics of the Canada-China canola trade dispute. Canadian Journal of Agricultural Economics 67: 251-60. [CrossRef]

Dickey, David A., and Wayne A. Fuller. 1979. Distribution of the estimators for autoregressive time series with a unit root. Journal of the American Statistical Association 74: 427-31.

Dickey, David A., and Wayne A. Fuller. 1981. Likelihood ratio statistics for autoregressive time series with a unit root. Econometrica 49: 1057-72. [CrossRef]

Enders, Walter, and Pierre L. Siklos. 2001. Cointegration and threshold adjustment. Journal of Business and Economic Statistics 19: 166-76. [CrossRef]

Engle, Robert F., and Clive W. J. Granger. 1987. Co-integration and error correction: Representation, estimation, and testing. Econometrica 55: 251-76. [CrossRef]

Food and Agricultural Organization of the United States. 2021. Crops and Livestock Products. Available online: http://www.fao.org/ faostat/en/\#data/TP (accessed on 15 July 2021).

Gonzalo, Jesús, and Jean-Yves Pitarakis. 2002. Estimation and model selection based inference in single and multiple threshold models. Journal of Econometrics 110: 319-52. [CrossRef]

Hassanzoy, Najibullah, Shoichi Ito, Hiroshi Isoda, and Yuichiro Amekawa. 2017. Cointegration and spatial price transmission among wheat and wheat-flour markets in Afghanistan. Applied Economics 49: 2939-55. [CrossRef]

Higgins, Vaughan, and Jacqui Dibden. 2011. Biosecurity, trade liberalisation, and the anti(politics) of risk analysis: The Australia-New Zealand apples dispute. Environment and Planning A: Economy and Space 43: 393-409. [CrossRef]

Leftfield Commodity Research. 2019. Canola Price Data.

Rude, James, Jared Carlberg, and Scott Pellow. 2007. Integration to fragmentation: Post-BSE Canadian cattle markets, processing capacity, and cattle prices. Canadian Journal of Agricultural Economics 55: 197-216. [CrossRef]

Rude, James, Javed Iqbal, and Derek Brewin. 2006. This little piggy went to market with a passport: The impacts of U.S country of origin labeling on the Canadian pork sector. Canadian Journal of Agricultural Economics 54: 401-20. [CrossRef]

Sanogo, Issa, and Mahamane Maliki Amadou. 2010. Rice market integration and food security in Nepal: The role of cross-border trade with India. Food Policy 35: 312-22. [CrossRef]

Sephton, Peter S. 2011. Spatial arbitrage in Sarawak pepper prices. Canadian Journal of Agricultural Economics 59: 405-16. [CrossRef]

Sephton, Peter, and Janelle Mann. 2013. Threshold cointegration, model selection with an application. Journal of Economics and Econometrics 56: 54-77.

Statistics Canada. 2021. Exports of Grains, by Final Destination; Series V125138 and V125173; Available online: https://www150.statcan. gc.ca/n1/en/type/data (accessed on 15 July 2021).

Wells, Jacob, and Peter Slade. 2021. The effect of the Canada-China canola trade dispute on canola prices. Canadian Journal of Agricultural Economics 60: 141-49. [CrossRef] 